A FEW REMARKS ON THE EARLY HISTORY OF RECTAL DISEASES.

Read before the Mississippi Valley Medical Society, Hot Springs, Ark. Nov. 3. 1894 .

BY B. G. GANT, M.D. KANSAS CITY, MO.

In the selection of historic medicine for my sub. ject, I am well aware that $I$ have chosen one that is rarely touched upon in medical societies and the current literature of the day. The study of the history and progress of medicine has ever been of great interest to me. I well remember, when holding down the benches at college, how the class used to enjoy a brief change from our routine lectures, when one of the professors would tell us about the heroes of medicine hundreds of years ago, and how such men as Hippocrates, Celsus, Galen, and others of the ancients, practiced the art and science of medicine; we listened attentively and marveled at their accuracy of diagnosis and the practical manner in which they effected a cure; this, too, with their meager knowledge of anatomy and physiology.

The science of medicine and surgery extends its inquiries over such a vast field, and comprehends such an enormous mass of facts and observations, that it would be impossible in a paper of this length to give more than a brief resumé of the history of one special department of medicine, which, I trust will be of some interest to this society, viz., that of rectal diseases.

I believe with that scholarly physician, William Bodenhamer, that there is no class of diseases within the whole range of medical literature which has a more ancient history, a more hoary antiquity, and a more conspicuous sacredness than some forms of rectal disease. In fact, the history of this class of diseases embraces all ages, including Hebraic, ancient and modern history. Medical men have, from the time of Adam down to the present day, devoted much time and study to these diseases. The first recorded mention of rectal diseases that we know of was made by Moses, the law-giver. This can be found in the fifth book of the old Bible. After explaining to the Jews the manner in which they would be rewarded if they strictly carried out the laws of God, he goes on to say: "And if thou wilt not hearken unto the voice of the Lord, and observe his commandment then all these curses shall come upon thee." $\mathrm{He}$ then records a number of curses; the only one of interest to us, however, is the following: "The Lord will smite thee with the botch of Egypt and with the emrods (hemorrhoids), whereof thou canst not be healed." Now, if we turn to I. Samuel, v. 5, we find the following bit of interesting information: He telis us that the Philistices took the ark of the Isord from Ebenezer and brought it unto Ashdod, and forthwith the hand of the Lord was heavy against them, and $\mathrm{He}$ smote the men of the cities both small and great, and they had the emrods in their secret parts." Again, in Psalms IxXviII, v. 66, we find recorded that He smote $\mathrm{His}$ enemies in the hinder parts. The ark of the Lord was then removed to Gath and Eckron with the hope that the plague, (emrods) would be removed, but such was not the case; on the contrary, these cities were alike afflicted. The people then began to seek a way in which they might rid themselves of their afflictions, and to this end they sought out the priests, and inquired what they must do to obtain relief. It is of interest to note the man- ner in which the cure was effected. It appears that after consultation, the priests and divines told the people to return the ark of the Lord to the Israelites from whom they had taken it; but it must not be returned empty. They must make a trespass offering of five golden images of the "emrods," according to the number of the lords of the Philistines; "for one plague is on you all, and all your lords. Do this, and thou shalt be healed."

It is stated on good authority that the natives in the far East at the present time make images of their afflicted parts and offer them to their gods as a trespass offering, and believe that through them alone can they obtain relief, many of their places of worship being burdened with such offerings. From the fact that the Israelites were threatened with the plague previously referred to, some writers have argued that the Jews from then down to our time are more frequently afflicted with rectal diseases of a hemorrhoidal nature than any other race of people. They teach that this malady is inherited by the Israelites, and that it is entailed upon them and their posterity forever, because of spiritual disobedience. From my limited study of Hebraic and ancient history, together with my personal experience in the treatment of these diseases among all races, both in private and hospital practice, I have been unable to obtain any evidence to substantiate such a claim. On the contrary, I have had ample opportunity and have noted that the Jew s are no more liable to be afflicted with rectal diseases than other people. Again, there is not a single instance in the Bible where it states that the Israelites ever had this threatened punishment inflicted upon them. On the other hand, there is abundant evidence to show that the plague with which the Jews were threatened was visited upon the Philistines some three hundred years thereafter, for stealing the ark. In view of the limited evidence at our command, I believe we are justified in concluding that the Jews are no more liable to be afflicted with any form of rectal disease as a result of divine punishment, than are the Gentiles. Unfortunately, we have no definite knowledge of the exact pathologic meaning of the Biblical term, "emrods," so frequently mentioned in the Scriptures. This is owing to the wide diversity of opinions of the Biblical commentators. Some took it to mean a dis. ease similar to bleeding piles; others, that there was a prolapsus of the bowel which remained out until it became putrid and sloughed off; and others took it to be some form of dysentery, and not a few that it was of a fistulous nature. The Greeks, Hippocrates, Galen, and others, evidently thought it to be a diseased condition of the rectal veins, accompanied by hemorrhage, for they substituted the word hemorrhoids for the Scriptural one, "emrods." Ever since that time, hemorrhage from the rectum has been diagnosed as such. It would appear from the writings of the ancients that some thought the hemorrhage active; others, that it was passive. It seems that they never mentioned anything about swellings or protrusions. Accoraing to our more modern teaching, the term hemorrhoids is applied to almost any swelling about the anal region, no matter whether there be hemorrhage or not. It at once becomes evident then that this term, as used by the early writers, was a misnomer and did not express the exact pathologic condition present, only the most prominent symptom. Leaving the Hebraic 
and turning to that of ancient history, we find frequent mention of certain forms of rectal diseases, also the plan of treatment adopted.

It is gratifying to note that in many instances the treatment suggested by the Greeks, Celsus, Hippocrates, Galen, and Rhazenand Abbas, the Arabian physicians and others of the ancients is practiced by the surgeons of our time with very slight modifications. This demonstrates the fact that they were not altogether wrong in their pathology though they were lacking in the knowledge of anatomy and physiology that we possess. I have neither the time or inclination to pay more than a passing glance at the treatment followed by the ancients in some of the more common forms of rectal diseases. Fissures were described as superficial erosions, cracks, or chaps, and, being slow to heal, the treatment consisted in converting them into recent ulcers by paring, scarifying, or incising them with the finger nail or scalpel when they were made to heal by topical applications. Hemorrhoids were ligated as to-day, except that the skin was not severed to prevent after-pain. Those who did not favor the ligature method used the cautery by puncturing the tumors, in addition to which various drugs were used locally. Fistula was accurately described by them and so far as I can find out their treatment consisted principally of setons and the local application of various drugs.

Many of the ancient writers believed that divine power must be enlisted in order that a cure might be effected in the various forms of rectal diseases. Others believed that an "amulet" was necessary; that to carry something in their pocket-a piece of metal, a precious stone, or a certain kind of nut or vegetable would cure them, and this practice is not abandoned to-day. For many of our own countrymen carry with them a buckeye or a horse-chestnut when suffering from piles or fistula, as an "amulet" for their relief or cure. Many patients have told me of remarkable cures effected in this way. The Irish potato comes next in favor to the buckeye, and it must be "dug out of the garden when the moon is right," put in the left trouser pocket, and is never to be removed under any circumstances. After a time they shrink up until they are no larger than a pigeon egg and are as hard as a rock. Then they will cure the worst case of piles. From the time of the Greek writers down to about the fifteenth century there is nothing recorded that would be of especial interest in this paper, but about this time or a century later, the writings about different diseases were very prolific and have continued so ever since. The reason given why the surgeons previous to this time said nothing about this class of diseases was because of the false delicacy in those who had them in not letting it be known. Again, in olden times most rectal diseases were considered incurable, and for a person to have an incurable disease was to have a disgraceful one; hence, these persons suffered on in silence lest they reveal their disgrace, and be ostracized by society. We find a very interesting instance of this in a treatise on "The Fistula of the Anus," originally written in Latin by John Astruc about 1715 , the first individual work of the kind ever written, a copy of which I possess and value highly. $\mathrm{He}$ says, "of late years (about 1700) was a case of fistula scarce seen or heard of by the physicians of the last age. But when once Louis XIV., King of France, labored under this complaint it became fashionable, and a vast multitude of these cases suddenly presented themselves, and after the King's example every one made an open and voluntary confession of this once secret disorder." $\mathrm{He}$ then records a parallel case, by Pliny, in the reign of Tiberius Cæsar; he says, "the cholic first showed itself, nor did one man in Rome ever complain of this disorder until the Emperor had been severely attacked by it." Fistula in ano has been immortalized by Shakespeare in his play "All's Well That Ends Well," based upon the King's hav. ing a fistula. This play is said to have been written in 1606. Again, the great historian, Hume, in writing of the death of King Henry V., who died about the year 1422, says he was seized with a fistula, a malady which the surgeons at that time had not the skill to cure. It is said that Louis XIV. deferred having an operation by the knife for many months though his attending surgeon, Monsieur Felix, insisted that such an operation was necessary if he anticipated a cure. As the laity became aware that their sovereign was suffering from a fistula many cures were suggested by physicians, priests, and others who claimed that they had effected many remarkable cures by their respective methods and who took this opportunity to gain His Majesty's favor. After deliberating he determined to give each one a chance to prove his assertions, but he was too long-headed to have the experiments tried on his own person. He set apart a wing in the palace and placed a number of his subjects in the various rooms who were suffering from fistula, and all of the various remedies suggested, together with a number of mineral waters said to always effect a cure in fistula cases, were given a trial. Not in a single instance was a cure effected. At last the King, to whom Monsieur Felix gave an account of the experiments, determined to have the operation performed. One morning when nothing of the kind was expected by the courtiers it was done, several incisions being made. This happened on Nov. 21, 1687. The cicatrization was well managed and the King perfectly cured. His Majesty royally recompensed Monsieur Felix and his assistants, the total amount of the fee being $\$ 73,500$. These were "royal days for surgeons," says a writer in the Medical Chirurgical Review. Immediately after the King's recovery this disease became fashionable and hundreds of people flocked to Monsieur Felix to be operated on for this complaint. It is even hinted that certain courtiers who previous to this time had concealed their afflictions, selected Versailles as the place to be operated on, for here the King would hear of their indisposition. One writer goes so far as to say that some of them did not have fistula at all, and were much put out when informed that an operation was not necessary.

My paper has now reached such a length that it would burden you, should I endeavor to even mention the various operations and methods of treatment that have been brought forward during the last four or five hundred years. The investigations of the various important diseases affecting the terminal portion of the colon, have during this time been prosecuted with very considerable ardor, and the advantages gained in consequence have been markedly progressive; for this knowledge we are indebted among others to such celebrated surgeons as Brodie, Allingham, Cooper, M. Boyer, Dupuyren, Van Buren, Bushe, Smith, Salmon, Curling, Ashton, Whitehead, Bodenhamer, Matthews, Kelsey, Cook and others, I was about to 
omit the name of that ingenious surgeon, Calvert, whose tallow candle led to the idea of the treatment of stricture by bougies.

In concluding my paper, I wish to read a few verses from Erichsen's Medical Rhymes written by a patient while undergoing treatment for stricture. It is said he left them on his physician's desk just before taking his departure for Niagara Falls, "where the water runs down hill with nothing on earth to hinder it."

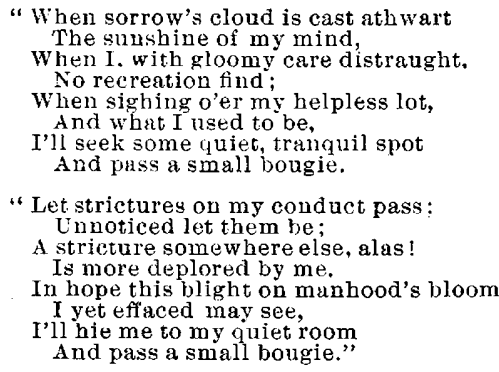

In the preparation of this paper I have made frequent reference to the following works: Bodenhamer, on the Rectum and Anus, 1855. Anal Fissures, 1868, and Hemorrhoidal Diseases, 1884. Frichsen, on Medical Rhymes, 1884. Paul, of London, on Lower Bowel, 1869. John Astruc, on the Fistula of the Anus, in Latin originally, and translated into English by John Freke, F.R.S., London, in 1738.

\section{FIBROUS POLYPUS OF THE RECTUM.}

Read before the Delaware County Medical Society.

BY G. W. H. KEMPER, M.D., AND HUGH A. COWING, M.D. MUNCIE, IND.

The specimen here presented is one of fibrous polypus recently removed from the rectum of a giri aged 6 years. At various times before the removal of the tumor, the child had passed slight quantities of bloody mucus, and the mother, at times, had noticed a fleshy mass presenting at the anal orifice. The father had applied to us for medicine for piles, lut the exceeding rarity of hemorrhoids in children led us to suggest to him to bring her in for examination; and that it was probably a case of polypus. This was confirmed upon examination. The tumor was attached by a long slim pedicle to the rectal wall nearly an inch above the external sphincter. After the expulsion of a warm water enema the polypus came in to full view, and its size and attachment determined. A ligature was thrown around it near its junction with the pedicle and the tumor was removed, there being but alight hemorrhage. The pedicle was restored to the rectum (without a ligature). Chloroform anesthesia was employed.

According to Parvin, polypus of the rectum is rare in the adult; still rarer in either adult or child is rectal fibrous polypus.

Gross refers to the uncommonness of polypi in the rectuni, and divides them into two classes: "Gelatinous or adenoid, and fibrous"; the former being of far more frequent occurrence.

Allingham remarks that "polypi of the rectum are usually described as being of two kinds, the soft or follicular, and the hard or fibrous; the former being found in children and the latter in grown persons." He also states: "I quite concur in the statement that the soft polypus is the one always found in children, but I am of the opinion that the fibrous variety is rare, even in the adult." Subsequently he states that he does not remember meeting in his practice "with more than six distinctly fibrous polypi".

Dr. Parvin (Trans. Indiana State Medical Society,
1873, p. 113) in his interesting article on "Fibrous Polypus of the Rectum," gives the following history: "Mrs. - 42 years of age, a widow, states, that for nearly four years she bas suffered from pain in the rectum, tenesmus, hemorrhages, and that for some months past the bowel has prolapsed whenever evacuated, requiring her to replace it. Besides-this is her narrative-the bowel comes forward into the vagina and presses against the urethra, causing frequent and sometimes difficult urination. Sitting for any length of time gives her great uneasiness while in a recumbent position she is comparatively comfortable. By medical advice she has used astringent injections for the hemorrhage, which is supposed to result from piles. No examination, however, has been made. The patient lying on her back, with her limbs drawn up, digital examination of the vagina and then of the rectum determined the presence in the latter of a hard polypus, attached by a long thin pedicle to the anterior rectal wall, two inches above the anus. Immediately the tumor was brought outside of the rectum. a ligature applied to the pedicle and the latter divided below the point of ligation."

\section{A REPORT OF TWO CASES OF LEPROSY IN} NATIVE-BORN CITIZENS OF OHIO.

\section{BY J. G. McDOUGAL, M.D.}

NEW LEXINGTON, OHIO.

On Dec. 19, 1894, there appeared before the New Lexington Board of Pension Examiners, Hannah M. Garey, an applicant for pension as a dependant child of George W. Carey, a deceased soldier of the One Hundred and Eighty-Seventh Regiment, Ohio Infantry. Examination disclosed that she was a victim of anesthetic leprosy, the following manifestations of which she presented: The left hand and distal third of fore-arm were swollen and rather firmly thickened, the hand and wrist being about twice the normal size. The distal phalanges of all the fingers were lost and the stumps healed. The thumb was slightly flexed, the nail deformed, thickened and discolored. The hand was being amputated at the radio-carpal articulation by a narrow encircling ulcerative process and the work was so near completion that only the ulnar vessels and a few tendons attached the hand. Both surfaces were covered by granulations and bathed with extremely foul-smelling pus. The right hand and fingers were swollen and clubbed, the distal phalanges of all the fingers lost, and the thumb affected as the left.

Both feet were swollen to one and a half times normal size and the swelling also involved the lower third of legs. The first three toes of each foot were lost at middle of proximal phalanges and the little toes at distal joints. The remaining toes were clawed and the nails deformed. In the middle of left sole was a deep ulcer from which there was a very offensive discharge. All the affected members were decidedly anesthetic-the thermal anesthesia being especially marked. There was an anesthetic bleb, the size of a silver quarter, on outer side of right arm just above elbow. The tongue, lips and nose were scarred and somewhat deformed from ulcerations that had healed.

The subject of this description is 18 years of age and this malady began to manifest itself when she was fifteen months old. In two or three years the toes began to ulcerate and come off; and the hands became involved, the flesh ulcerating from the fingers leaving the blackened dry bones exposed and these she persistently drummed on the tables and chairs until her mother cut them off with shears. She menstruated regularly from the time she was 14 years of age until about one year ago when menses ceased. The drain from the amputating ulcer which 